\title{
Estimation of Blast Severity on Rye and Triticale Spikes by Digital Image Analysis
}

\author{
João Leodato Nunes Maciel, ${ }^{1}$ Alfredo do Nascimento Junior, ${ }^{1}$ and Cristina Boaretto ${ }^{2}$ \\ ${ }^{1}$ Embrapa Trigo, BR-285, Km 294, CP 451, 99001-970 Passo Fundo, RS, Brazil \\ ${ }^{2}$ Faculdade de Agronomia e Medicina Veterinária, UPF, Campus I, BR-285, Bairro São José, CP 611, 99052-900 Passo Fundo, \\ RS, Brazil
}

Correspondence should be addressed to João Leodato Nunes Maciel; joao.nunes-maciel@embrapa.br

Received 9 July 2013; Accepted 5 September 2013

Academic Editor: A. V. Barker

Copyright (C) 2013 João Leodato Nunes Maciel et al. This is an open access article distributed under the Creative Commons Attribution License, which permits unrestricted use, distribution, and reproduction in any medium, provided the original work is properly cited.

In Brazil, more efficient methods are a necessity for evaluating blast severity on spikes in the breeding programs of rye, triticale, wheat, and barley. The objective of this work was to determine the feasibility of assessing blast severity based on the analysis of digital images of symptomatic rye and triticale spikes. Triticale and rye genotypes were grown to anthesis in pots and were then inoculated with a mixture of Magnaporthe oryzae isolates. Blast severity on the spikes was evaluated visually and after that the spikes were detached and photographed. Blast severity was determined using the program ImageJ to analyze the obtained images. Two methods of image analysis were used: selection of symptomatic areas using a mouse cursor (SCU) and selection of symptomatic areas using image segmentation (SIS). The SCU method was considered the standard reference method for determining the true value of blast severity on spikes. An analysis of variance did not determine any difference among the evaluation methods. The coefficient of determination $\left(R^{2}\right)$ obtained from a linear regression analysis between the variables SIS and SCU was 0.615. The obtained data indicate that the evaluation of blast severity on spikes based on image segmentation is feasible and reliable.

\section{Introduction}

Blast disease, caused by Magnaporthe oryzae B. Couch (anamorph. Pyricularia oryzae Cavara), is a major constraint to food production in the world, affecting crops of high agricultural importance, such as rice. Since the mid-1980s, blast has also constituted one of the most serious problems for wheat crops in South America, especially in Brazil, Bolivia, and Paraguay. In Brazil, among the crops known as "winter cereals," the problem transcends wheat fields, affecting triticale and rye. Despite being relatively minor crops in terms of occupied area, these crops suffer significantly from blast. The first observation of the disease in rye fields was in 1995, in Paraná State [1]. It was observed in triticale in the same year, in experiments conducted at Embrapa Cerrados, Planaltina, DF [2]. In general, blast is as difficult to control in these two crops as it is in wheat. The adoption of management practices such as crop rotation, balanced fertilization, and fungicide application on the aerial parts of the plants is not enough to prevent blast damage, especially in seasons of severe epidemics.

A contributing factor to the significant blast damage that is observed in Brazilian fields is the susceptibility of available rye and triticale cultivars. This situation demonstrates that the development of cultivars with better levels of resistance to blast is an essential component of disease control strategies. Improving the evaluation process of genotypes in relation to the disease would be valuable for this endeavor. One alternative that has successfully improved genotype evaluation is the analysis of digital images of diseased plants [3-12]. The advantage of this strategy over the conventional method of visual evaluation of disease severity is that it provides greater accuracy and reliability, although it does require image capturing devices and more specialized operators.

When evaluating disease severity using digital image analysis, it is important to understand that it is not possible to accurately assess the lesion area or the proportion of diseased area to the entire plant without a reference standard. 
According to Madden et al. [13], it is necessary to find the "actual" value of disease (i.e., the "true value" or "gold standard"). There are currently several software packages that make it possible to find the "actual" value of a particular disease. ImageJ is a program that has several options for digital image analysis [14], including the option to select areas affected by lesions using a mouse cursor. The program allows for the accurate determination of the value of these areas as well as a determination of their proportion of the total plant or affected segment.

The objective of this work was to determine the feasibility of assessing blast severity on rye and triticale based on the analysis of digital images of symptomatic spikes.

\section{Materials and Methods}

This work was conducted in the laboratory of plant pathology and in the greenhouse of Embrapa Wheat, in Passo Fundo, Rio Grande do Sul State (RS). The isolates used in the experiments were the monoconidial field isolates of $M$. oryzae $P y 11.151, P y 11.152$, and $P y 11.153$, obtained in October 2011 from rye plants of the cultivars BRS Serrano, BR 1, and IPR 89, respectively. These plants were in experimental plots in an area of Embrapa Wheat, Passo Fundo, RS.

2.1. Inoculation and Plant Evaluation. Isolates preserved on filter paper were transferred to Petri dishes containing an oatmeal agar medium and were incubated at $23-25^{\circ} \mathrm{C}$ for 12 days. To prepare the inoculum, the plates were washed with distilled water plus Tween-80 ( 2 drops/L). Five hundred $\mathrm{mL}$ of a suspension formed by mixing spores of the three strains of $M$. oryzae mentioned above, at a concentration of $2 \times 10^{5}$ conidia/mL, was used to inoculate the rye and triticale genotypes shown in Table 1 . The genotypes used in the experiment belong to the progenitor bank of the Embrapa wheat, rye, and triticale breeding program and are widely used in crosses to generate new cultivars. Plants of each genotype were grown in three pots, each containing three plants. Before inoculation, the plants were acclimatized at $24^{\circ} \mathrm{C}$ for $24 \mathrm{~h}$. The plants were inoculated at anthesis, in Zadok's growth stages 60-69 [15]. Late tillers of each plant were removed before inoculation, leaving 6 to 12 similarstage spikes per pot, from which 5 were randomly selected for evaluation. The experiment was conducted twice in a completely randomized design.

After inoculation, the plants were incubated in a growth chamber at $24^{\circ} \mathrm{C}$ with alternate light and dark periods of $12 \mathrm{~h}$, under nebulization of $120 \mathrm{~s}$ at intervals of $60 \mathrm{~s}$. After the first $24 \mathrm{~h}$, the humidity of the chamber was altered, with a nebulization of $60 \mathrm{~s}$ every $1800 \mathrm{~s}$. The plants were kept under these conditions for 4 days. After a postinoculation period of 5 days, the plants were placed outdoors under natural conditions, where they stayed for 6 more days until the last evaluation. The daily relative humidity $(\mathrm{RH})$ and minimum and maximum temperature during the period in which the plants were kept outdoors ranged from 60 to $87 \%, 11.3$ to $16.3^{\circ} \mathrm{C}$, and 22.2 to $27.8^{\circ} \mathrm{C}$, respectively. Spike disease severity was evaluated by visual assessment three times: at 7, 9, and 11 days after inoculation (dai). All emerged spikes (5 to 18/pot) were evaluated; however, only 5 spikes from each pot, chosen randomly, were considered in the statistical analysis. The severity data were used to determine the area under the disease progress curve (AUDPC) for each genotype.

2.2. Capturing and Processing Images. Soon after visual assessment at 11 dai (Figure 1(a)), the 5 spikes that were considered in the statistical analysis of each pot were collected; their stems were cut with a pair of scissors, and they were placed in identified paper bags and were kept at $-20^{\circ} \mathrm{C}$. The 5 spikes from each pot were placed in a different paper bag. The process of capturing images started 7 days after this procedure. Initially, the spikes were hydrated by placing them in a beaker of water for approximately $30 \mathrm{~min}$. They were then allowed to dry on a paper towel for approximately $10 \mathrm{~min}$. Photographs were taken of each group of five spikes obtained from each pot. The spike beards were removed before taking the photographs to avoid contrast that might interfere with the camera's focus. The spikes were placed on white sheets of paper on a laboratory bench, with a ruler placed on the bottom or on the left side of the sheets (Figure 1(a)). The spikes were positioned so that the most symptomatic side faced the camera.

The images of the spikes were captured with a Sony Cybershot digital camera DSC/-H7/H9 (Sony, Brazil), handheld approximately $50 \mathrm{~cm}$ above the spikes. Each image was compressed and saved in joint photographic experts group (JPEG) format as input for the ImageJ program [14], which was used to analyze the digital photographs. The unit used to measure the total, healthy, and symptomatic areas of the spikes was $\mathrm{cm}^{2}$, which was established based on the calibration dimensions made from the ruler scale that was below or beside the spike. A binary pattern of colors was used to determine the total area of the spikes, that is, the color black, on a white background (Figures 1(b), 1(c), and 1(e)).

Based on the characteristics of the ImageJ program, two methods were adopted to select and quantify the area affected by the disease on the spikes: selection of symptomatic areas with the mouse cursor (SCU, Figures 1(d) and 1(e)) and selection of symptomatic areas by image segmentation (SIS, Figure 1(b), [16, 17]). Using the SCU method, the diseased spike area was calculated by subtracting the nondiseased spike area (marked with the mouse cursor) from the total spike area. The disease severity on the spikes was obtained by transforming the numerical data to percentage data. Using the SIS method, the program itself differentiated the colors on the spikes, classifying the darker areas as healthy and the clearer areas as diseased. The same principle of subtracting areas and transforming data from numerical to percentage, as described above, was used to obtain the values of blast severity on the spikes. The ImageJ program was used under the following conditions: 8 bits/pixel, $0.1 \%$ saturation of pixels, all particles considered ( 0 to infinity), and photosensitivity with $65 \%$ noise tolerance.

2.3. Statistical Analysis. The statistical analysis was conducted using the SAS program (SAS Institute, Cary, NC, 
TABLE 1: (A) Triticale and (B) rye genotypes used in the work.

\begin{tabular}{|c|c|c|c|}
\hline $\mathrm{N}^{\circ}$ & Genotype & Characteristic & Genealogy \\
\hline \multicolumn{4}{|l|}{ (A) } \\
\hline 1 & BRS 203 & Cultivar & LT-1/Rhino \\
\hline 2 & BRS Minotauro & Cultivar & Octo92-3(PF89358/CenteioBR1)/TriticaleBR4 \\
\hline 3 & BRS Netuno & Cultivar & Pollmer $/ / 2^{*}$ Erizo/Bull \\
\hline 4 & BRS Saturno & Cultivar & PFT512/CEP28Guará \\
\hline 5 & BRS Ulisses & Cultivar & Erizo/Nimir \\
\hline 6 & Embrapa 53 & Cultivar & LT1117.82/Civet//CEP23Tatu \\
\hline 7 & IPR 111 & Cultivar & ANOAS5/STIER13 \\
\hline 8 & P.007132 & Line & Embrapa53/PFT0415 \\
\hline 9 & P.007171 & Line & BRSNetuno/Embrapa53 \\
\hline 10 & P.008166 & Line & BRS148/IPR111 \\
\hline 11 & PFT 0610 & Line & Embrapa53//PFT116/Hoh-87102-6-1 \\
\hline 12 & PFT 0705 & Line & Embrapa53//PFT116/Hoh-87102-6-1 \\
\hline 13 & PFT 0706 & Line & LT-1/Rhino \\
\hline 14 & PFT 0905 & Line & DAHBI_6/3/ARDI_1/TOPO 1419//ERIZO_9/4/SONNI_3 \\
\hline 15 & PFT 0906 & Line & $\begin{array}{l}\text { GAUR_2/HARE_3//JLO 97/CIVET/5/DIS } \\
\text { B5/3/SPHD/PVN//YOGUI_6/4/KER_3/6/150.83//2*TESMO_1/MUSX 603/7/GAUR_2/... }\end{array}$ \\
\hline 16 & PFT 0910 & Line & SUSI_2/5/TAPIR/YOGUI_1//2* MUSX/3/ERIZO_7/4/FARAS_1/6/VARSA_2/7/754.3/IBEX//BUF_1 \\
\hline 17 & PFT 1002 & Line & Embrapa18*2/HOH-85110-1-2 \\
\hline 18 & PFT 1005 & Line & ERIZO_10/2* BULL_1-1//CAAL/4/2* PACA_2/COPI_1-1/3/ARDI_1/TOPO 1419//ERIZO_9 \\
\hline 19 & PFT 1103 & Line & ARDI_1/TOPO 1419//ERIZO_9/3/LIRON_1-1/4/FAHAD_4/FARAS_1/5/CT775.81/ARDI_1//ANOAS_1 \\
\hline 20 & TPOLO 0608 & Line & 804/BAT/3/MUSX/LYNX//STIER_12-3/4/VARSA_3-1/5/FAHAD_8-1*2//HARE_263/CIVET \\
\hline 21 & TPOLO 0629 & Line & $\begin{array}{l}\text { STIER_22-1/NIMIR_3/6/IA- } \\
\text { T/M2A//PI/3/BGL/5/H277.69//TOR/TOB/3/FS1029/4/MERINO/7/TAPIR/YOGUI_1/... }\end{array}$ \\
\hline 22 & TPOLO 3-8 & Line & ERIZO_6/NIMIR_4//ERIZO_15/FAHAD_3 \\
\hline 23 & TPOLO 61 & Line & PRESTO//2TESMO_1/MUSX 603/4/ARDI_1/TOPO 1419//ERIZO_9/3/SUSI_2 \\
\hline \multicolumn{4}{|r|}{ ( } \\
\hline 24 & BR 1 & Cultivar & Selected in landrace populations from Rio Grande do Sul State \\
\hline 25 & BRS Serrano & Cultivar & Crossing between population Garcia and population Bagé \\
\hline 26 & IPR 89 & Cultivar & Selected in coming populations from Australia \\
\hline 27 & PFS 0605 & Line & Selected in sister lines of the cultivar IPR 89 \\
\hline
\end{tabular}

USA). The rye and triticale genotypes were compared using the AUDPC, the disease severity registered by the SCU and SIS methods, and visual assessment at 11 dai. The data were subjected to analysis of variance (ANOVA), and the discrimination of the variation among genotypes was performed using the Tukey test at 5\% probability. The three methods were compared with each other by subjecting the data to ANOVA. Linear regression analysis was conducted between methods, including the AUDPC. The AUDPC data were not submitted to ANOVA along with the other methods of assessing severity because they measure a different variable. The AUDPC represents the sum of three severity observations for each genotype, while the other methods rely on only one observation. The severity values were transformed into arc-sen square root $(X / 100)$, while the AUDPC values were transformed to the square root of $x+10$. The SAS program was also used to conduct the tests of significance of the linear regression analysis established between each two variables evaluated in the work $\left(F, t\right.$, and $R^{2}$; Steel and [18]).

\section{Results}

The tested genotypes showed a high degree of susceptibility to blast. Differences in assessed severity among the 27 tested genotypes were observed, measured in four different ways, that is, the AUDPC, SCU, SIS, and visual assessment at 11 dai (Tables 2 and 3). However, the Tukey test for these four different types of evaluations showed that most of the genotypes used in the experiment were statistically equal to each other in relation to disease severity. Such genotypes are characterized by severity and AUDPC values exactly the same letter in Table 2 and were formed by groups with 24, 16,24 , and 22 components according to the method used 


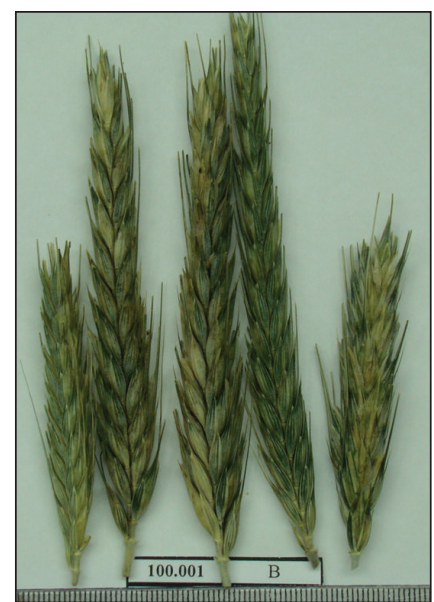

(a)

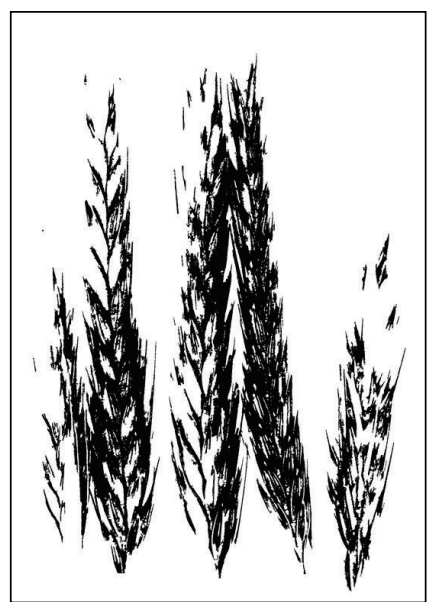

(b)

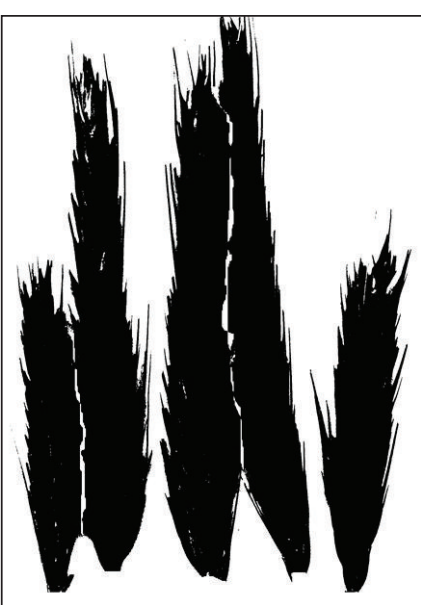

(c)

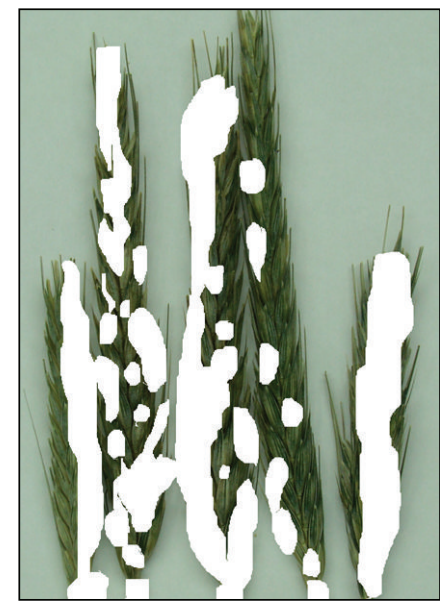

(d)

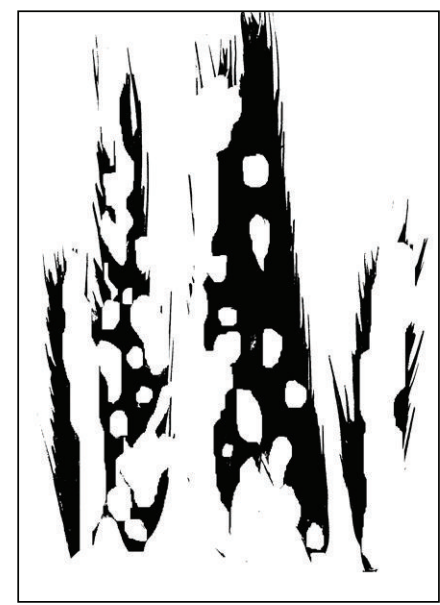

(e)

FIGURE 1: Assessment of blast severity on spikes of the BRS 203 triticale cultivar by digital image analysis. (a) Symptomatic spikes. (b) Selection of symptomatic areas by image segmentation (SIS method). (c) Total spike areas considered. (d) Selection of symptomatic areas with mouse cursor (SCU method). (e) Application of binary pattern of colors on the SCU method (the white area is diseased; the black is healthy).

to assess the infection: SCU, SIS, visual assessment at 11 dai, and AUDPC, respectively. It is therefore possible to say that the four types of evaluations were performed comparably to classify the genotypes in terms of reaction to blast, considering that the compositions of the above mentioned groups were very similar. The four methods used to assess infection were performed similarly for classifying genotypes as nonbelonging to the larger groups mentioned above. The triticale line TPOLO 61 (number 23, Table 1) represents this case, having been the genotype that was found to be the most resistant to blast according to the three methods based on spike evaluation performed only one time (SCU, SIS, and visual assessment) and having the second lowest value of AUDPC. The triticale line PFT 0610 (number 11, Table 1) was ranked as the most susceptible in three of the four evaluation methods. The only exception was when the SCU method was used.

Most of the severity values (51 out of 81 samples) obtained using the SIS method were higher than those obtained using the SCU method. After reducing the severity values of these 51 samples by $5 \%$, an ANOVA did not determine any differences among the three evaluation methods based on a single observation of the spikes, that is, when the comparison was conducted among SCU, SIS, and visual assessment at 11 dai (data not shown). Five percent of reduction was an arbitrary correction factor chosen to become the values obtained by SIS method more similar to the values obtained by the SCU method.

The results of the linear regression analysis of the data series of each pair of variables evaluated in this work are presented in Table 3 . The $F$ - and $t$-tests determined significance in the linear association between these four variables when compared pairwise. The $R^{2}$ (coefficient of determination) test determined significance at $P<0.01$ for the associations SIS $\times$ SCU and AUDPC $\times$ visual assessment at 11 dai (Figure 2). The $R^{2}$ test determined significance at $P<0.05$ for the associations SCU $\times$ AUDPC and SCU $\times$ visual assessment at 11 dai. 


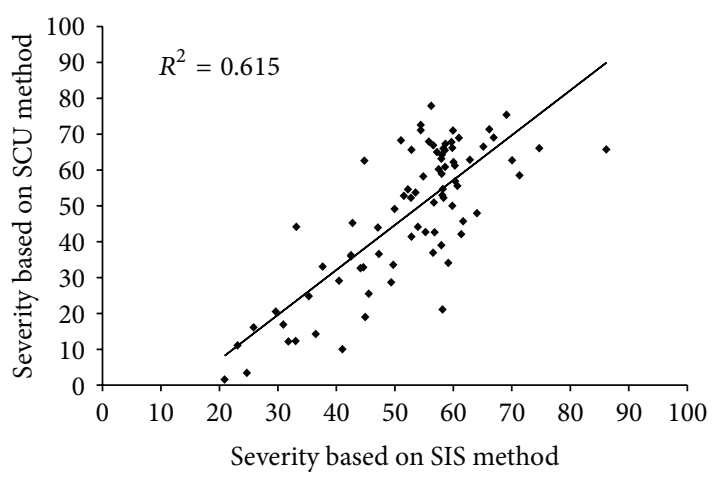

(a)

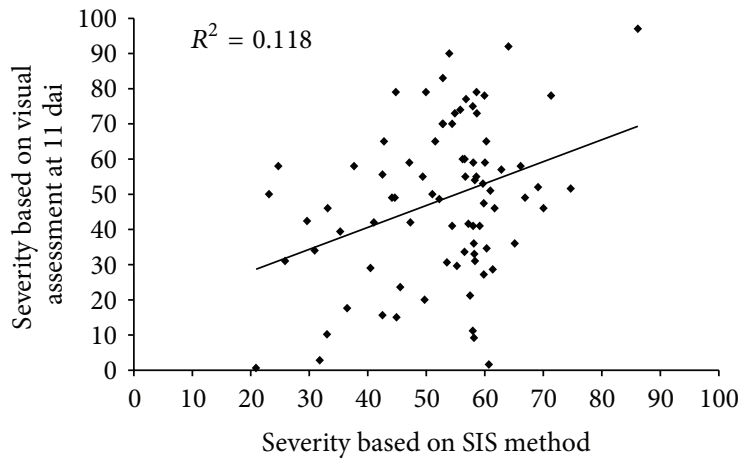

(c)

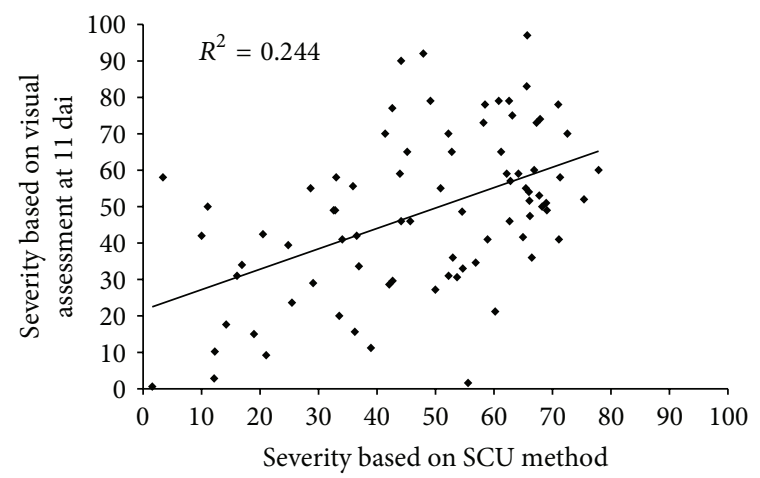

(e)

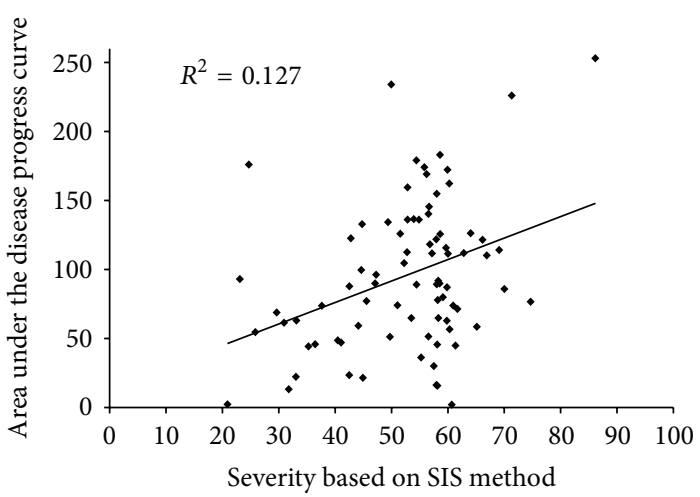

(b)

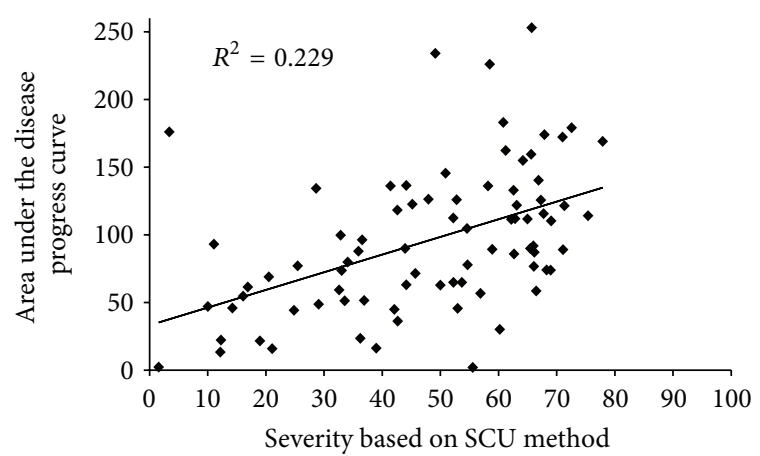

(d)

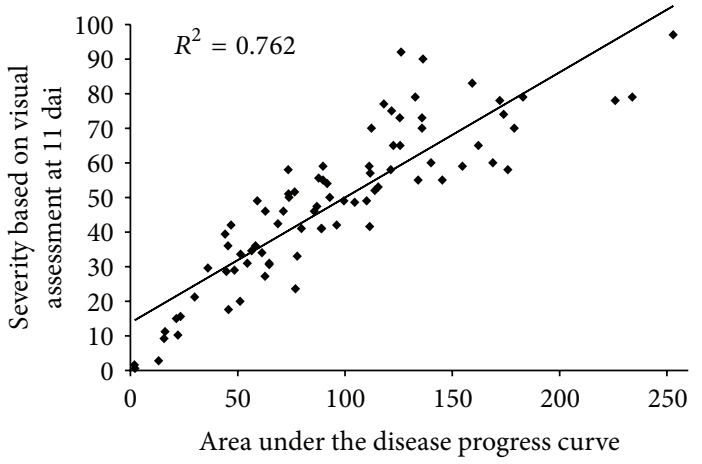

(f)

FIGURE 2: Regression analysis between methods of assessing blast severity on rye and triticale spikes ((a)-(f)). SCU: selection of symptomatic areas with mouse cursor; SIS: selection of symptomatic areas by image segmentation; dai: days after inoculation.

\section{Discussion}

Although a relatively small number of spikes were used in each assay (405/assay), it was not possible to carry out all evaluation procedures and image capturing in a single day, namely, at 11 dai, when the third blast visual assessment was conducted for all genotypes. For this reason, spikes were frozen at $-20^{\circ} \mathrm{C}$ to ensure that the disease had the same amount of time to develop on the spikes of all genotypes. It is clear that the large-scale adoption of digital image analysis for blast severity evaluation requires more efficient methods for data collection so that all activities can be executed in a single day.
It is important to emphasize that the SCU method must be considered the method with the greatest potential to be the most precise and accurate, having been classified as the "method of truth." We took into account the opinion of Madden et al. [13], who asserted that without an estimate of the actual disease value, it is not possible to assess the accuracy of the measurement. There are reports about studies using other strategies for determining the actual disease value. It is possible, for example, from photos taken of symptomatic plants or segments of symptomatic plants, to dissect the diseased from healthy parts, to weigh them, and to perform an analysis based on the proportion of the two types of indentation pieces $[19,20]$. In the present work, the 
TABLE 2: Blast severity and the area under the disease progress curve (AUDPC) on rye and triticale spikes assessed visually and by analysis of digital images.

\begin{tabular}{|c|c|c|c|c|c|c|c|}
\hline \multicolumn{2}{|c|}{ SIS method } & \multicolumn{2}{|c|}{ SCU method } & \multicolumn{2}{|c|}{ Visual assessment } & \multicolumn{2}{|c|}{ AUDPC } \\
\hline 11 & $70.00^{\mathrm{a}}$ & 6 & $71.33^{\mathrm{a}}$ & 11 & $81.67^{\mathrm{a}}$ & 11 & $219.33^{\mathrm{a}}$ \\
\hline 9 & $66.69^{\mathrm{ab}}$ & 9 & $71.07^{\mathrm{a}}$ & 18 & $79.00^{\mathrm{a}}$ & 1 & $171.07^{\mathrm{ab}}$ \\
\hline 15 & $63.47^{\mathrm{ab}}$ & 11 & $65.60^{\mathrm{ab}}$ & 15 & $71.20^{\mathrm{ab}}$ & 18 & $148.80^{\mathrm{abc}}$ \\
\hline 4 & $63.47^{\mathrm{ab}}$ & 16 & $61.57^{\mathrm{ab}}$ & 1 & $66.67^{\mathrm{ab}}$ & 2 & $138.67^{\mathrm{abc}}$ \\
\hline 12 & $61.36^{\mathrm{ab}}$ & 22 & $59.20^{\mathrm{ab}}$ & 10 & $61.67^{\mathrm{ab}}$ & 10 & $127.53^{\mathrm{abc}}$ \\
\hline 3 & $60.32^{\mathrm{ab}}$ & 18 & $56.73^{\mathrm{ab}}$ & 20 & $58.67^{\mathrm{ab}}$ & 6 & $123.20^{\mathrm{abc}}$ \\
\hline 5 & $60.32^{\mathrm{ab}}$ & 4 & $56.20^{\mathrm{ab}}$ & 19 & $56.33^{\mathrm{ab}}$ & 20 & $109.60^{\mathrm{abc}}$ \\
\hline 22 & $58.78^{\mathrm{abc}}$ & 15 & $55.40^{\mathrm{ab}}$ & 14 & $54.73^{\mathrm{ab}}$ & 8 & $109.20^{\mathrm{abc}}$ \\
\hline 7 & $57.76^{\mathrm{abc}}$ & 3 & $54.37^{\mathrm{ab}}$ & 16 & $53.33^{\mathrm{ab}}$ & 19 & $107.67^{\mathrm{abc}}$ \\
\hline 6 & $56.25^{\mathrm{abc}}$ & 5 & $53.70^{\mathrm{ab}}$ & 17 & $53.07^{\mathrm{ab}}$ & 15 & $105.07^{\mathrm{abc}}$ \\
\hline 16 & $55.25^{\mathrm{abc}}$ & 12 & $52.67^{\mathrm{ab}}$ & 26 & $52.33^{\mathrm{ab}}$ & 14 & $103.87^{\mathrm{abc}}$ \\
\hline 14 & $54.76^{\mathrm{abc}}$ & 7 & $50.87^{\mathrm{ab}}$ & 2 & $52.00^{\mathrm{ab}}$ & 16 & $103.07^{\mathrm{abc}}$ \\
\hline 17 & $54.76^{\mathrm{abc}}$ & 1 & $48.80^{\mathrm{ab}}$ & 8 & $50.67^{\mathrm{ab}}$ & 9 & $97.93^{\mathrm{abc}}$ \\
\hline 18 & $54.76^{\mathrm{abc}}$ & 14 & $48.67^{\mathrm{ab}}$ & 9 & $48.67^{\mathrm{ab}}$ & 3 & $92.87^{\mathrm{abc}}$ \\
\hline 21 & $53.78^{\mathrm{abc}}$ & 8 & $47.77^{\mathrm{ab}}$ & 3 & $48.47^{\mathrm{ab}}$ & 17 & $91.40^{\mathrm{abc}}$ \\
\hline 1 & $52.32^{\mathrm{abc}}$ & 21 & $46.50^{\mathrm{ab}}$ & 6 & $47.53^{\mathrm{ab}}$ & 12 & $80.53^{\mathrm{abc}}$ \\
\hline 8 & $48.53^{\mathrm{abc}}$ & 13 & $44.97^{\mathrm{ab}}$ & 13 & $42.53^{\mathrm{ab}}$ & 26 & $80.20^{\mathrm{abc}}$ \\
\hline 10 & $47.61^{\mathrm{abc}}$ & 17 & $44.70^{\mathrm{ab}}$ & 27 & $41.53^{\mathrm{ab}}$ & 13 & $73.20^{\mathrm{abc}}$ \\
\hline 2 & $46.24^{\mathrm{abc}}$ & 20 & $42.47^{\mathrm{ab}}$ & 22 & $39.20^{\mathrm{ab}}$ & 27 & $73.00^{\mathrm{abc}}$ \\
\hline 13 & $44.00^{\mathrm{abc}}$ & 10 & $42.23^{\mathrm{ab}}$ & 4 & $37.73^{\mathrm{ab}}$ & 22 & $71.00^{\mathrm{abc}}$ \\
\hline 26 & $43.12^{\mathrm{abc}}$ & 26 & $41.43^{\mathrm{ab}}$ & 24 & $37.20^{\mathrm{ab}}$ & 4 & $62.40^{\mathrm{abc}}$ \\
\hline 20 & $42.68^{\mathrm{abc}}$ & 19 & $40.63^{\mathrm{ab}}$ & 12 & $37.07^{\mathrm{ab}}$ & 24 & $62.33^{\mathrm{abc}}$ \\
\hline 19 & $40.96^{\mathrm{abc}}$ & 2 & $39.77^{\mathrm{ab}}$ & 5 & $35.60^{\mathrm{ab}}$ & 5 & $60.47^{\mathrm{abc}}$ \\
\hline 25 & $40.53^{\mathrm{bc}}$ & 25 & $26.67^{\mathrm{ab}}$ & 7 & $33.40^{\mathrm{ab}}$ & 21 & $60.27^{\mathrm{abc}}$ \\
\hline 24 & $39.69^{b c}$ & 27 & $26.67^{\mathrm{ab}}$ & 21 & $27.20^{\mathrm{ab}}$ & 7 & $46.13^{b c}$ \\
\hline 27 & $39.27^{b c}$ & 24 & $26.53^{\mathrm{ab}}$ & 25 & $23.33^{\mathrm{ab}}$ & 23 & $30.00^{c}$ \\
\hline 23 & $29.88^{c}$ & 23 & $13.53^{\mathrm{b}}$ & 23 & $14.67^{\mathrm{b}}$ & 25 & $29.70^{c}$ \\
\hline Mean & 51.63 & & 47.78 & & 48.35 & & 95.50 \\
\hline $\mathrm{CV}(\%)^{\mathrm{c}}$ & 11.93 & & 25.63 & & 29.13 & & 21.84 \\
\hline
\end{tabular}

${ }^{\mathrm{a}}$ The numbers in the first column of each assessment method refer to the genotypes listed in Table 1.

${ }^{\mathrm{b}}$ In each column, means followed by the same letter are not significantly different at $P<0.05$.

${ }^{\mathrm{c}} \mathrm{CV}$ values were obtained from performed ANOVA with transformed data.

SCU: selection of symptomatic areas with mouse cursor; SIS: selection of symptomatic areas by image segmentation.

selection of the injured areas with the mouse cursor on the computer, which was the basis of the SCU method, proved to be efficient for determining blast severity on the spikes. This statement is based mainly on the fact that an ANOVA did not verify differences among the three evaluation methods based on a single observation of spikes (SCU, SIS, and visual assessment at 11 dai; data not shown).

The linear regression analysis did not give the same results provided by the ANOVA when the three methods (SCU, SIS, and visual assessment at 11 dai) were compared and considered to be equivalent methods for severity evaluation (Figure 2). This assertion is made taking into account the $R^{2}$ obtained from a linear regression analysis, which indicated nonsignificance in the linear association between SIS $\times$ visual assessment at 11 dai, as well as in the association between SIS $\times$ AUDPPC. These results indicate that the data obtained by the SIS method were not as close to the data obtained through visual assessment. However, any conclusions on the subject must take into account that the subjective nature of visual assessment of disease severity may introduce considerable errors [21-25] situation that, possibly, influenced the coefficient of variation (CV) obtained in this study, which were relatively high in the assessments made with SCU, visual assessment at 11 dai, and AUDPC methods (Table 2). The possibility that visual assessment may not be as accurate as other methods can be suggested, given that the association between SCU $\times$ visual assessment at 11 dai and SCU $\times$ AUDPPC had relatively low $R^{2}$ values of 0.244 and 0.229 , respectively, although both were classified as significant at $P<0.05$ (Figures 2(d) and 2(e)).

The "basis" of this work is not the genotypes used but the method of blast severity evaluation and the comparison between the data obtained using the SIS and SCU methods is the most relevant analysis conducted. The importance of this 
TABLE 3: Statistical tests applied to the analysis of linear regression between the methods of assessing blast severity on rye and triticale spikes.

\begin{tabular}{lccc}
\hline Evaluated relationship & \multicolumn{3}{c}{ Statistical test } \\
& $F$ & $t$ & $R^{2}$ \\
\hline SIS versus SCU & $123.972^{* *}$ & $11.135^{* *}$ & $0.615^{* *}$ \\
SIS versus AUDPC & $11.526^{* *}$ & $3.395^{* *}$ & $0.127^{\mathrm{NS}}$ \\
$\begin{array}{l}\text { SIS versus visual } \\
\text { assessment at 11 dai }\end{array}$ & $10.597^{* *}$ & $3.255^{* *}$ & $0.118^{\mathrm{NS}}$ \\
$\begin{array}{l}\text { SCU versus AUDPC } \\
\text { SCU versus visual }\end{array}$ & $23.411^{* *}$ & $4.839^{* *}$ & $0.229^{*}$ \\
$\begin{array}{l}\text { assessment at 11 dai } \\
\text { AUDPC versus visual } \\
\text { assessment at 11 dai }\end{array}$ & $25.553^{* *}$ & $5.055^{* *}$ & $0.244^{*}$ \\
\hline
\end{tabular}

Statistical tests: $F: F$-test; $t$ : Student's $t$-test; $R^{2}$ : coefficient of determination. Significance terms: NS: not significant; ${ }^{*} P<0.05 ;{ }^{* *} P<0.01$.

SIS: selection of symptomatic areas by image segmentation method; SCU: selection of symptomatic areas with mouse cursor; AUDPC: area under the disease progress curve; dai: days after inoculation.

analysis lies primarily in how the data were obtained in the SCU method (method of truth), which must be considered as the most reliable for measuring the actual blast in the spikes. For this reason, the $R^{2}$ value of 0.615 (Figure 2(a)), obtained from the linear regression analysis between the SCU and SIS methods, is significant at $P<0.01$ and constitutes an important indication that the evaluation of blast severity on spikes using digital images is feasible and reliable. The fact that an ANOVA showed no difference between the SIS and SCU methods for evaluating blast severity on all 27 genotypes used in the experiment (Table 2) corroborates these statements.

Although a highly accurate system for assessing blast severity on spikes based on digital image analysis is desirable, there is no evaluation method as fast as visual assessment, and evaluators in the field are irreplaceable. Disease severity can be assessed very quickly in the field by scoring a large group of plants that make up a plot. The present work demonstrates that the analysis of digital images has certain advantages over this method, such as keeping the genotype reactions preserved and, most importantly, providing the potential for greater precision and accuracy.

One important point in favor of the use of the digital analysis method in rye and triticale is the lack of immunity to blast that genotypes of both crops have demonstrated, as mentioned in this work. These circumstances indicate that partial or quantitative resistance is the most viable alternative for obtaining cultivars more resistant to blast in the field. In this way, the SIS method provides a level of detail that is extremely relevant in quantitative assessments related to partial resistance. However, in situations in which a very large number of genotypes need to be evaluated, the large-scale adoption of a digital image analysis method requires a functional infrastructure, in addition to training the people involved in data collection. On the other hand, digital cameras, such as the one used in this work, are relatively inexpensive items available to any breeding program worldwide.
It is reasonable to assume that the SIS method does not have the sensitivity required to differentiate lesions associated with diseases such as scab and glume blotch, caused by Gibberella zeae and Leptosphaeria nodorum, respectively. The differentiation made by the SIS method in this study was between the darkest (green and healthy) and the clearest (injured) colors and there is no way of differentiating something a little clearer from something a little darker, which may be necessary, for example, when evaluating lesions caused by scab. In such cases, an analysis of digitized images of diseases on triticale and rye spikes, or on spikes of other species of cereals such as wheat and barley, requires that these spikes have homogeneous symptoms. Spikes with these characteristics can be obtained by assays conducted under controlled conditions involving the inoculation of plants with pure suspensions of the pathogen and in nurseries installed in places where there is a natural occurrence of a particular disease. In Brazil, considering wheat blast, or even rye and triticale blast, this last condition can be obtained in nurseries installed in regions of the Brazilian biome known as Cerrado, where the disease has a high level of prevalence during the heading time of these crops.

\section{References}

[1] Y. R. Mehta and A. Baier, "Variação patogênica entre isolados de Magnaporthe griseaatacando triticale e trigo no estado do Paraná," Summa Phytopathologica, vol. 24, pp. 119-125, 1998.

[2] J. R. N. Anjos, D. B. Da Silva, M. J. D. Charcar, and G. C. Rodrigues, "Ocorrência de brusone (Pyricularia grisea) em trigo e centeio na região dos cerrados do Brasil Central," Pesquisa Agropecuária Brasileira, vol. 31, pp. 79-82, 1996.

[3] I. S. Ahmad, J. F. Reid, M. R. Paulsen, and J. B. Sinclair, "Color classifier for symptomatic soybean seeds using image processing," Plant Disease, vol. 83, no. 4, pp. 320-327, 1999.

[4] G. C. G. Andrade, A. C. Alfenas, R. G. Mafia, L. A. Maffia, and R. C. Goncalves, "Diagrammatic scale for assessment of eucalyptus leaf spot severity caused by Quambalaria eucalypti," Fitopatologia Brasileira, vol. 30, pp. 504-509, 2005.

[5] C. H. Bock, P. E. Parker, A. Z. Cook, and T. R. Gottwald, "Characteristics of the perception of different severity measures of citrus canker and the relationships between the various symptom types," Plant Disease, vol. 92, no. 6, pp. 927-939, 2008.

[6] C. H. Bock, P. E. Parker, A. Z. Cook, and T. R. Gottwald, "Visual rating and the use of image analysis for assessing different symptoms of citrus canker on grapefruit leaves," Plant Disease, vol. 92 , no. 4 , pp. 530-541, 2008.

[7] C. H. Bock, A. Z. Cook, P. E. Parker, and T. R. Gottwald, "Automated image analysis of the severity of foliar citrus canker symptoms," Plant Disease, vol. 93, no. 6, pp. 660-665, 2009.

[8] N. J. Grünwald, M. Kitner, V. McDonald, and E. M. Goss, "Susceptibility in Viburnum to Phytophthora ramorum," Plant Disease, vol. 92, no. 2, pp. 210-214, 2008.

[9] E. G. Kokko, R. L. Conner, G. C. Kozub, and B. Lee, "Quantification by image analysis of subcrown internode discoloration in wheat caused by common root rot," Phytopathology, vol. 83, pp. 976-981, 1993.

[10] E. G. Kokko, R. L. Conner, B. Lee, A. D. Kuzyk, and G. C. Kozub, "Quantification of common root rot symptoms in resistant and susceptible barley by image analysis," Canadian Journal of Plant Pathology, vol. 22, no. 1, pp. 38-43, 2000. 
[11] S. A. Tjosvold and D. L. Chambers, "Correlation of lesion size with percent lesion coverage on camellia and rhododendron leaves inoculated with Phytophthora ramorum," Phytopathology, vol. 96, article S114, 2006.

[12] A. Vicent, J. Armengol, and J. García-Jiménez, "Rain fastness and persistence of fungicides for control of alternaria brown spot of citrus," Plant Disease, vol. 91, no. 4, pp. 393-399, 2007.

[13] L. V. Madden, G. Hughes, and F. van den Bosch, The Study of Plant Disease Epidemics, APS Press, St. Paul, Minn, USA, 2007.

[14] C. A. Schneider, W. S. Rasband, and K. W. Eliceiri, "NIH Image to ImageJ: 25 years of image analysis," Nature Methods, vol. 9, pp. 671-675, 2012.

[15] J. C. Zadoks, T. T. Chang, and C. F. Konzak, "A decimal code for the growth stages of cereals," Weed Research, vol. 14, no. 6, pp. 415-421, 1974.

[16] L. G. Shapiro and G. C. Stockman, Computer Vision, PrenticeHall, Englewood Cliffs, NJ, USA, 2001.

[17] W. Z. Shen, Y. Wu, Z. L. Chen, and H. D. Wei, "Grading method of leaf spot disease based on image processing," in Proceedings of the International Conference on Computer Science and Software Engineering (CSSE '08), vol. 6, pp. 491-494, IEEE Computer Society, Wuhan, China, December 2008.

[18] R. G. D. Steel and J. H. Torrie, Principles and Procedures of Statistics, McGraw-Hill, New York, NY, USA, 1960.

[19] R. T. Sherwood, C. C. Berg, M. R. Hoover, and K. E. Zeiders, "Illusions in visual assessment of Stagonospora leaf spot of orchardgrass," Phytopathology, vol. 73, pp. 173-177, 1983.

[20] M. Nita, M. A. Ellis, and L. V. Madden, "Reliability and accuracy of visual estimation of phomopsis leaf blight of strawberry," Phytopathology, vol. 93, no. 8, pp. 995-1005, 2003.

[21] G. A. Forbes and J. T. Korva, "The effect of using a HorsfallBarratt scale on precision and accuracy of visual estimation of potato late blight severity in the field," Plant Pathology, vol. 43, no. 4, pp. 675-682, 1994.

[22] T. T. Hebert, "The rationale for the Horsfall-Barratt plant disease assessment scale," Phytopathology, vol. 72, article 1269, 1982.

[23] F. W. Nutter Jr, M. L. Gleason, J. H. Jenco, and N. C. Christians, "Assessing the accuracy, intra-rater repeatability, and inter-rater reliability of disease assessment systems," Phytopathology, vol. 83, pp. 806-812, 1993.

[24] F. W. Nutter Jr. and P. M. Schultz, "Improving the accuracy and perception of disease assessments: selection of methods and use of computer-aided training programs," Canadian Journal of Plant Pathology, vol. 17, no. 2, pp. 174-184, 1995.

[25] C. H. Bock, G. H. Poole, P. E. Parker, and T. R. Gottwald, "Plant disease severity estimated visually, by digital photography and image analysis, and by hyperspectral imaging," Critical Reviews in Plant Sciences, vol. 29, no. 2, pp. 59-107, 2010. 


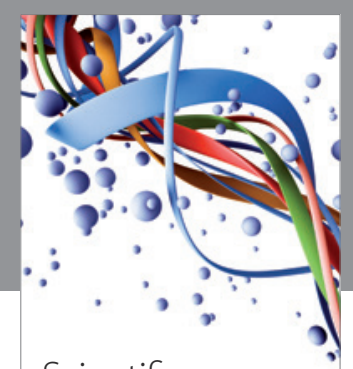

Scientifica
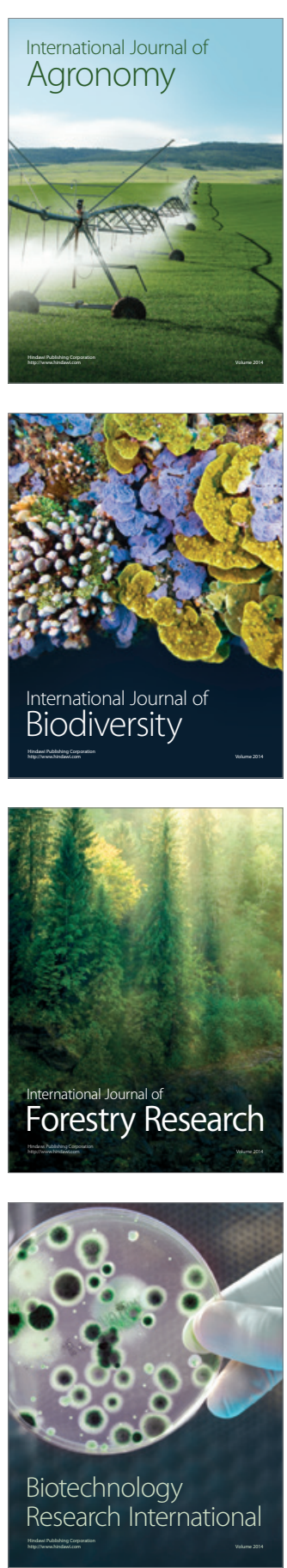
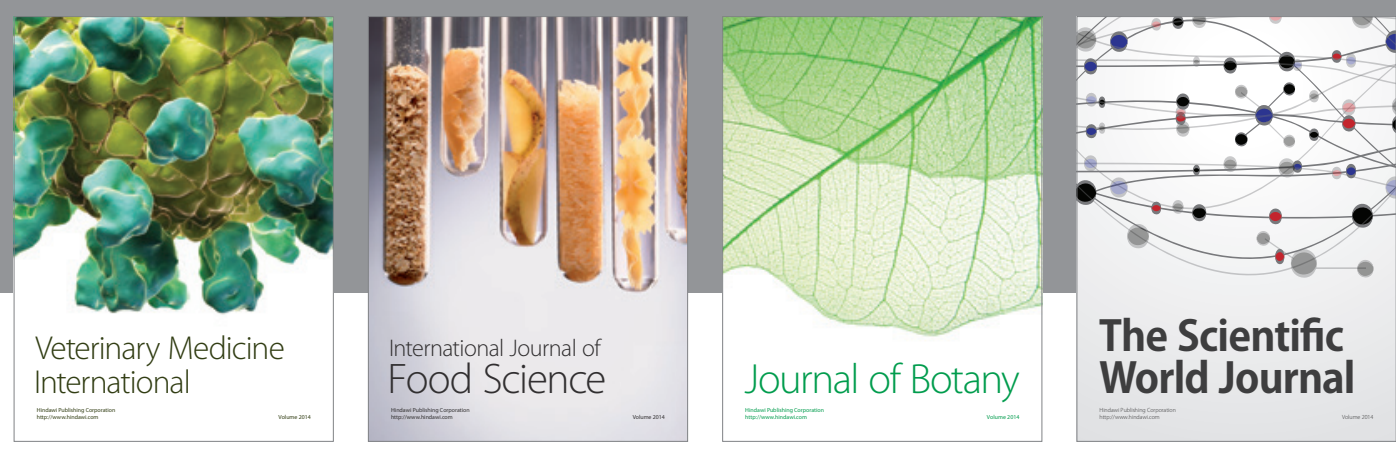

The Scientific World Journal
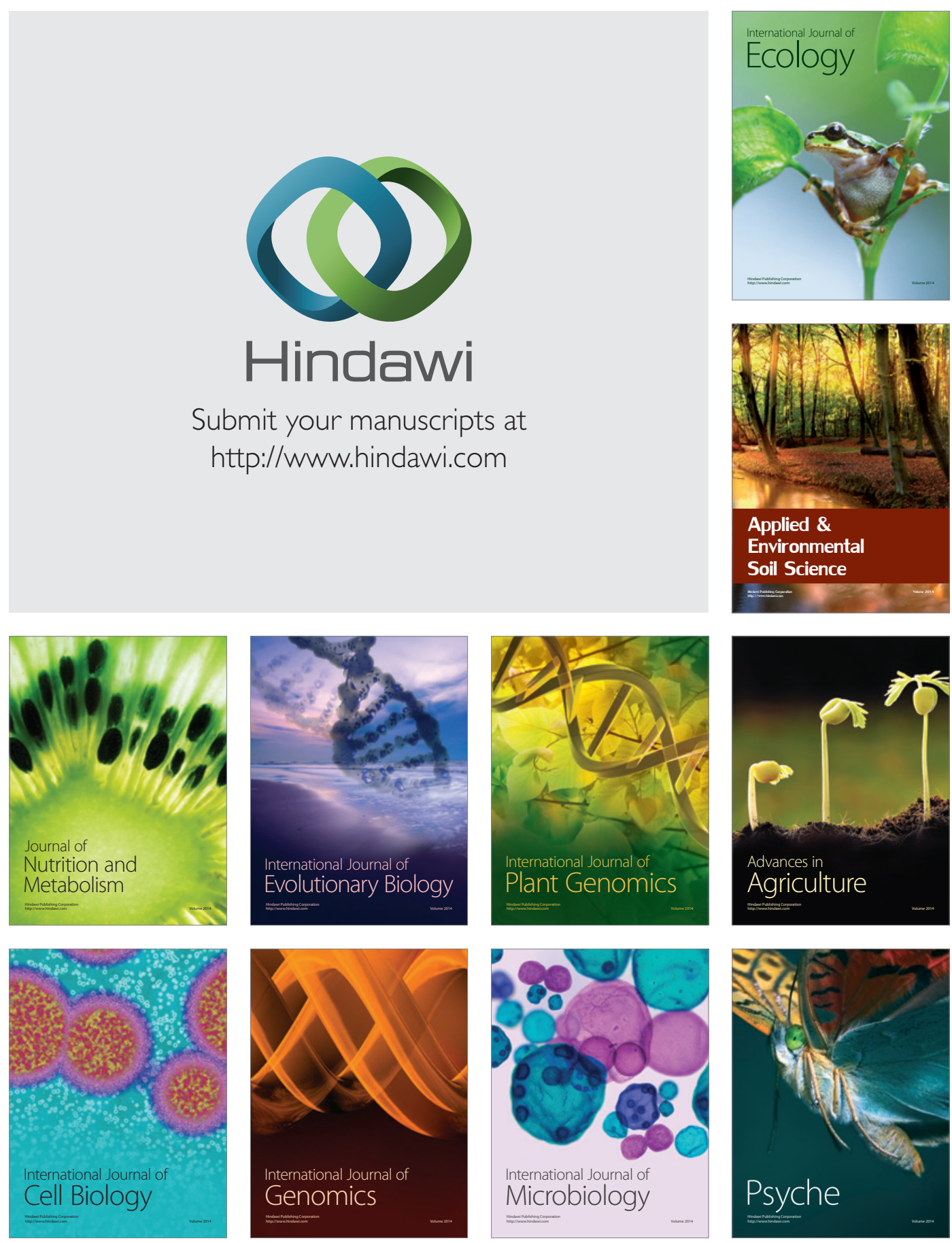